\title{
Dietary vitamin $C$ intake protects against COPD: the Korea National Health and Nutrition Examination Survey in 2012
}

This article was published in the following Dove Press journal:

International Journal of COPD

31 October 2016

Number of times this article has been viewed

Hye Jung Park,' Min Kwang Byun,' Hyung Jung Kim,' Jae Yeol Kim, ${ }^{2}$ Yu-II Kim, ${ }^{3}$ Kwang-Ha Yoo, ${ }^{4}$ Eun Mi Chun, ${ }^{5}$ Ji Ye Jung, ${ }^{6}$ Sang Haak Lee, ${ }^{7}$ Chul Min Ahn'

On behalf of the Korean Smoking Cessation Study Group

'Department of Internal Medicine, Gangnam Severance Hospital, Yonsei University College of Medicine, ${ }^{2}$ Department of Internal Medicine, Chung-Ang University College of Medicine, Seoul, ${ }^{3}$ Department of Internal Medicine, Chonnam National University Hospital, Gwangju, ${ }^{4}$ Department of Internal Medicine, Konkuk University School of Medicine, ${ }^{5}$ Department of Internal Medicine, Ewha Womans University School of Medicine, ${ }^{6}$ Division of Pulmonology, Department of Internal Medicine, Institute of Chest Disease, Severance Hospital, Yonsei University College of Medicine, ${ }^{7}$ Division of Pulmonology, Critical Care and Sleep Medicine, Department of Internal Medicine, College of Medicine, The Catholic University of Korea, Seoul, Korea

Correspondence: Chul Min Ahn Department of Internal Medicine, Gangnam Severance Hospital, Yonsei University College of Medicine, 2I I Eonju-ro Gangnam-gu, Seoul I35-720, Korea

Tel +82 220193317

Fax +82 234633882

Email ahn5302@yuhs.ac
Background: Vitamin C, as an antioxidant, has recently been suggested to provide protection against COPD; however, only few national cohort studies have investigated these effects. We aimed to confirm the protective effects of vitamin C against COPD in Korean patients.

Patients and methods: We analyzed the data of 3,283 adults aged $\geq 40$ years (representing $23,541,704$ subjects) who underwent pulmonary function tests and responded to questionnaires on smoking history and vitamin $\mathrm{C}$ intake, with stratification variables and sampling weight designated by the Korea 2012 National Health and Nutrition Examination Survey.

Results: Among all the subjects, 512 (representing 3,459,679 subjects; 15.6\%) were diagnosed as having COPD based on pulmonary function test results. Male gender, old age, residence in suburban/rural regions, low household income, low educational level, an occupation in agriculture or fisheries, and heavy smoking were significantly associated with COPD. Low intake of nutrients, including potassium, vitamin A, carotene, retinol, and vitamin $\mathrm{C}$, was significantly associated with COPD. The prevalence of COPD in heavy smokers with the lowest quartile (Q1, <48.50 mg; 63.0\%) and low-middle quartile (Q2, 48.50-84.38 mg; 56.4\%) of vitamin $\mathrm{C}$ intake was significantly higher than that in subjects with the high-middle quartile (Q3, 84.38-141.63 mg; 29.5\%) and highest quartile (Q4, >141.63 mg; 32.6\%) of vitamin C intake $(P=0.015)$. In multivariate analysis, male gender, old age, heavy smoking, and a low intake of vitamin $\mathrm{C}$ were significant independent risk factors for COPD. A significant reduction of 76.7\% in COPD risk was observed with a Q3 vitamin C intake compared to Q1 vitamin C intake (odds ratio, 0.233 ; 95\% confidence interval, 0.094-0.576) in heavy smokers.

Conclusion: This large-scale national study suggests that dietary vitamin C provides protection against COPD, independent of smoking history, in the general Korean population.

Keywords: chronic obstructive lung disease, vitamin C, nutrition, risk factor, smoking

\section{Introduction}

Antioxidant deficiency contributes to develop and aggravate various chronic diseases, including COPD which is sensitive to oxidative stress. Supplementation with vitamin C, as an antioxidant, improves antioxidant status in COPD. ${ }^{1}$ Several epidemiologic studies $^{2,3}$ and prospective studies ${ }^{4,5}$ revealed protective effects of vitamin $\mathrm{C}$ intake on COPD. Vitamin C has symptom-relieving effects on the exacerbation of COPD. ${ }^{6}$ In addition, it improves pulmonary function in COPD. ${ }^{7,8}$ Moreover, a recent animal study has revealed that supplementation with vitamin $\mathrm{C}$ not only prevents the development of COPD but also restores the lung function in COPD subjects. ${ }^{9}$

The Korea National Health and Nutrition Examination Survey (KNHANES) is a large-scale survey containing a vast amount of data on demographics, underlying 
disease, smoking history, lung function, and nutritional status, conducted by the Korean Centers for Disease Control and Prevention (KCDC). The sample in the present study was selected by a well-designed national program with a complex, multistage probability sample extraction. Therefore, the results obtained by this survey using complex analysis can be generalized to the entire Korean general population. ${ }^{10,11}$ Thus, KNHANES is the best tool for defining and confirming the correlation between vitamin $\mathrm{C}$ intake and COPD.

Therefore, in this study, we aimed to confirm the protective effects of vitamin $\mathrm{C}$ against COPD in the Korean general population using KNHANES data.

\section{Patients and methods}

\section{Study design and populations}

We analyzed the data from KNHANES V, the national survey performed in 2012. This survey used stratification and multiple stages of cluster selection to represent the entire Korean general population. We followed guidelines reporting the sample weight and stratification designated by the KCDC; this information is available at the KNHANES website to facilitate obtaining appropriate results, and all the raw data are open to the public (https://knhanes.cdc.go.kr). The institutional review board of Gangnam Severance Hospital approved this study (Approval Number: 3-2016-0195).

We included 3,283 subjects aged 40 years or older, who responded to the health interview survey, underwent pulmonary function tests, and responded to questionnaires on smoking history and vitamin C intake from January 2012 to December 2012. All participants provided a written informed consent form prior to conducting the survey.

\section{Interview items, including nutritional status}

All interview items, including nutritional status, were assessed by questioning the subjects in face-to-face interviews. The resident district was classified as urban (concordant with Dong) and suburban/rural (concordant with Eup/Myun). The type of residence was classified as apartment or general house. Household income was classified into 4 categories (lowest quartile, Q1; low-middle quartile, Q2; high-middle quartile, Q3; highest quartile, Q4). Vitamin C intake was also classified into 4 categories (Q1, <48.50 mg; Q2, 48.50-84.38 mg; Q3, 84.38-141.63 mg; Q4, >141.63 mg).

\section{Smoking history}

Smoking history was carefully reviewed using the questionnaire. The amount smoked (pack $\times$ year) was calculated based on the duration of smoking history (year), the amount of cigarettes smoked (pack/day), and the frequency of smoking (day/month). The amount smoked was obtained by multiplying these 3 parameters with 12 . Smoking history was classified into 4 categories according to the amount smoked (never smoker, 0 pack-years; light smoker, 0-20 pack-years; medium smoker, 20-40 pack-years; heavy smoker, $>40$ pack-years).

\section{COPD diagnosis}

Pulmonary function tests, including forced vital capacity (FVC) and forced expiratory volume in 1 second $\left(\mathrm{FEV}_{1}\right)$, were performed using commercially available equipment (Masterlab-IOS; Erich Jaeger Co., Friedburg, Germany) on all the subjects. COPD was defined as an $\mathrm{FEV}_{1} / \mathrm{FVC}$ ratio of $<0.7 .^{12}$

\section{Statistical analyses}

For complex sample survey data analysis, we used the KNHANES stratification variables and sampling weight. Between the non-COPD and COPD groups, differences in the mean age and nutritional status were assessed with the independent sample $t$-test, and differences in the categorized variables were tested using the chi-square test. The prevalence of COPD according to smoking history and the amount of vitamin $\mathrm{C}$ ingested was compared using the chi-square test. Univariate and multivariate analyses for COPD were performed using logistic regression tests. We used SPSS 18.0 (SPSS Inc., Chicago, IL, USA) statistical software. A $P$-value $<0.05$ was considered statistically significant.

\section{Results \\ Demographic characteristics according to COPD diagnosis}

We enrolled 3,283 subjects representing a total of 23,541,704 Korean subjects. Among all the subjects, 512 (representing 3,459,679 subjects; $15.6 \%$ ) were diagnosed as having COPD. We classified all subjects into 2 groups (non-COPD and COPD), and compared the demographic characteristics between the 2 groups. In males, the prevalence of COPD was significantly higher than that in females $(23.5 \%$ vs $6.6 \% ; P<0.001)$. The mean age ( \pm standard deviation) of the COPD group $(64.2 \pm 0.7)$ was significantly older than that in the non-COPD group $(54.5 \pm 0.4 ; P<0.001)$. The prevalence of COPD in subjects who live in suburban/rural areas was significantly higher than that in subjects living in urban areas $(20.8 \%$ vs $12.9 \% ; P<0.001)$. In subjects who lived in the general type of house, the prevalence of COPD 
was higher $(16.6 \%)$ than that in subjects who lived in an apartment $(9.3 \% ; P<0.001)$. The prevalence of COPD decreased according to the increase in household income $(P<0.001)$. Marital status was not a significant factor in COPD $(P=0.261)$. Subjects who worked in agriculture or fisheries showed a higher prevalence of COPD $(25.0 \%)$ than subjects who had a professional job (7.7\%), or had a service and sales job $(6.0 \% ; P<0.001)$. Among never smokers, the prevalence of COPD was $7.9 \%$, and the prevalence increased according to the increase in the amount smoked $(16.7 \%$ in light smokers; $24.2 \%$ in medium smokers; $45.3 \%$ in heavy smokers; $P<0.001$; Table 1).

\section{Comparison of nutritional status according to COPD}

We compared the nutritional status assessed by the selfreported questionnaire between the non-COPD and COPD group. The amount of food intake $(\mathrm{g})$ in the COPD group $(1,320.4 \pm 37.9)$ was significantly less than that in the nonCOPD group $(1,462.3 \pm 23.6 ; P=0.001)$. The amount of potassium (mg) ingested in the COPD group $(2,915.4 \pm 85.9)$ was significantly less than that in the non-COPD group $(3,200.0 \pm 58.9 ; P=0.005)$. The amount of vitamin $\mathrm{A}$ and carotene taken by the COPD group was also less than that in the non-COPD group ( $P=0.040$ and 0.015 , respectively).

Table I Demographic characteristics according to the diagnosis of COPD

\begin{tabular}{|c|c|c|c|c|c|}
\hline Variables & $\begin{array}{l}\text { Enrolled } \\
\text { number }\end{array}$ & $\begin{array}{l}\text { Representing } \\
\text { number }\end{array}$ & Non-COPD & COPD & $P$-value \\
\hline \multirow[t]{2}{*}{ Total number } & 3,283 & $23,54 I, 704$ & 2,77I (representing & 512 (representing & \\
\hline & & & $20,082,025)$ & $3,459,679)$ & \\
\hline Sex & & & & & $<0.001$ \\
\hline Male & I,376 & I I,252,028 & $8,604,056(76.5 \%)$ & $2,647,97 \mid(23.5 \%)$ & \\
\hline Female & I,907 & $12,289,677$ & I I,477,969 (93.4\%) & $8 \mathrm{I}, 708(6.6 \%)$ & \\
\hline Age (mean $\pm S D)$ & & & $54.5 \pm 0.4$ & $64.2 \pm 0.7$ & $<0.001$ \\
\hline Resident district & & & & & 0.006 \\
\hline Urban & 2,556 & $18,092,613$ & I5,766,726 (87.I\%) & $2,325,887(12.9 \%)$ & \\
\hline Suburban/rural & 727 & $5,449,091$ & 4,3 I5,299 (79.2\%) & $\mathrm{I}, \mathrm{I} 33,792(20.8 \%)$ & \\
\hline Type of residence & & & & & $<0.001$ \\
\hline General type & $\mathrm{I}, 836$ & $|7,367,74|$ & |4,484,857 (83.4\%) & $2,882,884(16.6 \%)$ & \\
\hline Apartment & $\mathrm{I}, 447$ & $6,173,963$ & $5,597,168(90.7 \%)$ & 576,795 (9.3\%) & \\
\hline Household income & & & & & $<0.001$ \\
\hline Lowest quartile (QI) & 670 & $4,438,281$ & $3,38 I, 82 I(76.2 \%)$ & $1,056,459(23.8 \%)$ & \\
\hline Low-middle quartile (Q2) & 837 & $6,259,228$ & $5,302,125(84.7 \%)$ & $957,103(15.3 \%)$ & \\
\hline High-middle quartile (Q3) & 787 & $5,895,330$ & $5,113,119(86.7 \%)$ & $782,2||(\mid 3.3 \%)$ & \\
\hline Highest quartile (Q4) & 949 & $6,651,449$ & $6,017,045(90.5 \%)$ & $634,404(9.5 \%)$ & \\
\hline Educational level & & & & & $<0.001$ \\
\hline Below elementary & 1,068 & $6,840,173$ & $5,289,636(77.3 \%)$ & I,550,537 (22.7\%) & \\
\hline Middle school & 495 & $3,255,797$ & $2,688,555(82.6 \%)$ & $567,242(17.4 \%)$ & \\
\hline High school & $\mathrm{I}, 008$ & $8,268,662$ & $7,323,906(88.6 \%)$ & $944,756(11.4 \%)$ & \\
\hline Above university & 707 & $5,137,213$ & $4,740,069(92.3 \%)$ & $397, \mid 44$ (7.7\%) & \\
\hline Marital status & & & & & 0.261 \\
\hline Married & $3,24 I$ & $23,120,165$ & 19,703,137 (85.2\%) & $3,4 \mid 7,028(\mid 4.8 \%)$ & \\
\hline Unmarried & 41 & 419,691 & $378,888(90.3 \%)$ & $40,803(9.7 \%)$ & \\
\hline Occupation & & & & & $<0.001$ \\
\hline Professional job & 344 & $2,899,674$ & $2,676,419(92.3 \%)$ & $223,255(7.7 \%)$ & \\
\hline Office job & 169 & $\mathrm{I}, 262,324$ & I,I0I, I49 (87.2\%) & 161,175 (12.8\%) & \\
\hline Service and sales & 408 & $3,387,293$ & $3,|84,80|(94.0 \%)$ & $202,491(6.0 \%)$ & \\
\hline Agriculture and fisheries & 339 & $2,181,427$ & $\mathrm{I}, 636,043(75.0 \%)$ & $545,384(25.0 \%)$ & \\
\hline Technician & 303 & $2,984,528$ & $2,485,055(83.3 \%)$ & $499,473(16.7 \%)$ & \\
\hline Laborer & 348 & $2,500,599$ & $2,068,775(82.7 \%)$ & 431,824 (I7.3\%) & \\
\hline Jobless & 1,363 & $8,256,867$ & $6,874,613(83.3 \%)$ & I,382,254 (I6.7\%) & \\
\hline Smoking history & & & & & $<0.001$ \\
\hline Never smoker & 2,012 & $13,162,867$ & |2, I |9,987 (92.1\%) & $\mathrm{I}, 042,880$ (7.9\%) & \\
\hline Light smoker & 625 & $5,155,829$ & $4,295,088$ (83.3\%) & 860,741 (I6.7\%) & \\
\hline Medium smoker & 446 & $3,837,658$ & $2,908,730(75.8 \%)$ & $928,928(24.2 \%)$ & \\
\hline Heavy smoker & 200 & I,385,350 & $758,220(54.7 \%)$ & $627,130(45.3 \%)$ & \\
\hline
\end{tabular}

Abbreviation: SD, standard deviation. 
Table 2 Comparison of nutritional status according to the COPD

\begin{tabular}{llll}
\hline Nutritional status & $\begin{array}{l}\text { Non-COPD (representing } \\
\text { number =20,082,025) }\end{array}$ & $\begin{array}{l}\text { COPD (representing } \\
\text { number =3,459,679) }\end{array}$ & $\begin{array}{c}\text { P-value } \\
\text { Food intake }(\mathrm{g})\end{array}$ \\
Protein intake $(\mathrm{g})$ & $\mathrm{I}, 462.3 \pm 23.6$ & $1,320.4 \pm 37.9$ & $0.00 I^{*}$ \\
Fat intake $(\mathrm{g})$ & $69.4 \pm \mathrm{I} . \mathrm{I}$ & $67.8 \pm 2.4$ & 0.560 \\
Carbohydrate intake $(\mathrm{g})$ & $36.6 \pm 0.9$ & $34.6 \pm 2.4$ & 0.407 \\
Calcium intake $(\mathrm{mg})$ & $322.9 \pm 4.2$ & $333.5 \pm 7.5$ & 0.180 \\
Potassium intake $(\mathrm{mg})$ & $514.0 \pm 10.6$ & $492.1 \pm 30.2$ & 0.490 \\
Vitamin A intake $(\mu \mathrm{gRE})$ & $3,200.0 \pm 58.9$ & $2,915.4 \pm 85.9$ & $0.005^{*}$ \\
Carotene intake $(\mu \mathrm{g})$ & $1,006.8 \pm 65.1$ & $797.3 \pm 82.2$ & $0.040^{*}$ \\
Retinol intake $(\mu \mathrm{g})$ & $5,392.4 \pm 39 I .3$ & $4,044.9 \pm 418.8$ & $0.015^{*}$ \\
Vitamin C intake $(\mathrm{mg})$ & $93.4 \pm 6.5$ & $63.8 \pm 4.9$ & $<0.00 I^{*}$ \\
\hline
\end{tabular}

Note: $* P<0.05$ between non-COPD and COPD group obtained by independent sample $t$-test.

Abbreviation: RE, retinol equivalent.

In the COPD group, the retinol intake $(63.8 \pm 4.9 \mu \mathrm{g})$ was significantly less than that in the non-COPD group $(93.4 \pm 6.5 \mu \mathrm{g}$; $P<0.001)$. The vitamin $\mathrm{C}$ intake $(\mathrm{mg})$ was also significantly less than that in the non-COPD group $(93.2 \pm 3.9$ vs $122.1 \pm 4.0$; $P<0.001$; Table 2).

\section{Prevalence of COPD according to smoking history and vitamin $C$ intake}

The prevalence of COPD was positively correlated with the amount of smoking, and negatively correlated with the amount of vitamin $\mathrm{C}$ ingested. In light smokers, the prevalence of COPD in subjects with vitamin C intake in Q1 (24.7\%) was significantly higher than that in subjects whose vitamin $\mathrm{C}$ intake fell in Q4 (7.0\%; $P=0.002)$. In heavy smokers, the prevalence of COPD in subjects with Q1 (63.0\%) and Q2 (56.4\%) vitamin C intakes was significantly higher than that in subjects with Q3 (29.5\%) and Q4 (32.6\%) vitamin $\mathrm{C}$ intakes $(P=0.015)$. In addition, the prevalence of COPD in heavy smokers with vitamin C intake in Q3 (29.5\%) was lower than that in medium smokers with Q1 vitamin C intake (36.8\%; Figure 1).

\section{Risk factors for COPD}

We selected significant risk factors for COPD using univariate analysis with logistic regression of all the variables used in Tables 1 and 2. Sex, age, resident district, type of residence, household income, educational level, occupation, smoking history, and amount of retinol intake and vitamin C intake were significant risk factors for COPD in the univariate analysis. In the multivariate analysis, sex, age, smoking history, and amount of vitamin $\mathrm{C}$ intake were independent risk factors for COPD. Female gender was a preventative factor (odds ratio [OR], 0.234; 95\% confidence interval [CI],
$0.144-0.378 ; P<0.001)$ compared to male gender. Aging was a significant risk factor (OR, 1.089; 95\% CI, 1.068-1.110; $P<0.001)$. Compared to never smokers, medium smokers (OR, 2.192; 95\% CI, 1.305-3.680) and heavy smokers (OR, 2.894; 95\% CI, 1.641-5.102) were at high risk for COPD $(P<0.001)$. The amount of vitamin $\mathrm{C}$ intake was a preventative factor for COPD independent of sex, age, and even smoking history (OR, 0.998; 95\% CI, 0.996-0.999; $P=0.001)$. A 1-mg increase of vitamin C intake reduced the risk of COPD by $0.2 \%$ (Table 3 ).

\section{Vitamin $C$ intake is protective against COPD in heavy smokers}

We classified the subjects according to smoking history, and subclassified them according to the amount of vitamin C ingested, and confirmed that the amount of vitamin $\mathrm{C}$ is an independent preventative factor for COPD when adjusted for age and sex. In light smokers, vitamin C intake in Q4

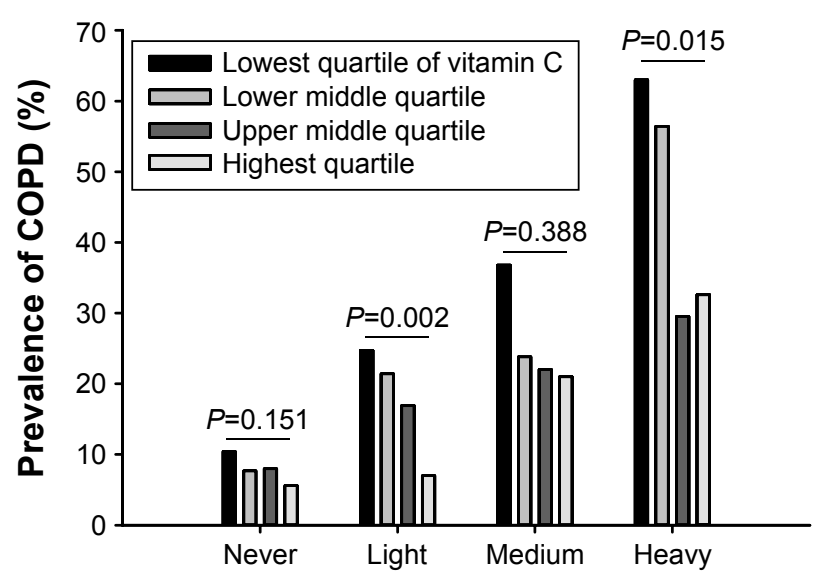

Figure I Correlation of the prevalence of COPD with the amount of smoking. 
Table 3 Univariate and multivariate analysis for COPD

\begin{tabular}{|c|c|c|c|c|c|c|}
\hline \multirow[t]{2}{*}{ Variables } & \multicolumn{3}{|c|}{ Univariate analysis } & \multicolumn{3}{|c|}{ Multivariate analysis } \\
\hline & OR & $95 \% \mathrm{Cl}$ & $P$-value & OR & $95 \% \mathrm{Cl}$ & $P$-value \\
\hline Sex & & & $<0.001$ & & & $<0.00 I^{*}$ \\
\hline Male & Reference & & & Reference & & \\
\hline Female & 0.230 & $0.173-0.306$ & & 0.234 & $0.144-0.378$ & \\
\hline Age & 1.080 & I.067-1.094 & $<0.001$ & 1.089 & $1.068-1.110$ & $<0.00 I^{*}$ \\
\hline Resident district & & & 0.006 & & & 0.601 \\
\hline Urban & Reference & & & Reference & & \\
\hline Suburban/rural & $1.78 \mid$ & $1.181-2.685$ & & I.I37 & $0.701-1.845$ & \\
\hline Type of residence & & & $<0.001$ & & & 0.387 \\
\hline General type & Reference & & & Reference & & \\
\hline Apartment & 0.518 & $0.379-0.707$ & & 0.855 & $0.598-1.222$ & \\
\hline Household income & & & $<0.001$ & & & \\
\hline Lowest quartile (QI) & Reference & & & Reference & & 0.806 \\
\hline Low-middle quartile (Q2) & 0.578 & $0.425-0.785$ & & 0.931 & $0.622-1.392$ & \\
\hline High-middle quartile (Q3) & 0.490 & $0.335-0.716$ & & I.I37 & $0.709-1.823$ & \\
\hline Highest quartile (Q4) & 0.338 & $0.225-0.507$ & & 1.043 & $0.633-1.718$ & \\
\hline Educational level & & & $<0.001$ & & & 0.354 \\
\hline Below elementary & Reference & & & Reference & & \\
\hline Middle school & 0.720 & $0.524-0.988$ & & 0.873 & $0.550-1.386$ & \\
\hline High school & 0.440 & $0.308-0.629$ & & 0.810 & $0.512-1.280$ & \\
\hline Above university & 0.286 & $0.192-0.424$ & & 0.601 & $0.346-1.046$ & \\
\hline Occupation & & & & & & 0.529 \\
\hline Professional job & Reference & & $<0.001$ & Reference & & \\
\hline Office job & 1.755 & $0.786-3.918$ & & 2.009 & $0.906-4.455$ & \\
\hline Service and sales & 0.762 & $0.342-1.697$ & & 0.805 & $0.322-2.012$ & \\
\hline Agriculture and fisheries & 3.996 & $2.015-7.927$ & & $\mathrm{I} .153$ & $0.504-2.64 I$ & \\
\hline Technician & 2.401 & $1.213-4.785$ & & 1.242 & $0.573-2.694$ & \\
\hline Laborer & 2.502 & $1.309-4.784$ & & 1.230 & $0.538-2.814$ & \\
\hline Jobless & 2.410 & $1.365-4.256$ & & 1.092 & $0.534-2.233$ & $0.001 *$ \\
\hline Smoking history & & & $<0.001$ & & & \\
\hline Never smoker & Reference & & & Reference & & \\
\hline Light smoker & 2.329 & $1.64 I-3.305$ & & 1.435 & $0.925-2.227$ & \\
\hline Medium smoker & 3.711 & $2.528-5.450$ & & 2.192 & $1.305-3.680$ & \\
\hline Heavy smoker & 9.612 & $6.368-|4.5| \mid$ & & 2.894 & $1.64 \mid-5.102$ & \\
\hline Nutrition & & & & & & 0.648 \\
\hline Retinol intake $(\mu g)$ & 0.998 & $0.996-0.999$ & 0.005 & 1.000 & $0.999-1.001$ & $0.001 *$ \\
\hline Vitamin C intake (mg) & 0.996 & $0.995-0.998$ & $<0.001$ & 0.998 & $0.996-0.999$ & \\
\hline
\end{tabular}

Note: ${ }^{*} P<0.05$ obtained by multivariate logistic regression analysis.

Abbreviations: $\mathrm{OR}$, odds ratio; $\mathrm{Cl}$, confidence interval.

was protective against $\mathrm{COPD}$, compared to vitamin $\mathrm{C}$ intake in Q2. In particular, in heavy smokers, the risk reduction rate in individuals with vitamin C intake falling in Q3 was 76.7\%, compared to those with vitamin $\mathrm{C}$ intake in Q1 (OR, 0.233; 95\% CI, 0.094-0.576; Table 4).

\section{Discussion}

We conducted a comprehensive study of COPD using the Korean national data. Various factors, including sex, age, resident district, type of residence, household income, educational level, occupation, and smoking history, affect the prevalence of COPD. In addition, we found that subjects living in suburban/rural areas and general residence types, and subjects with a low income, low educational level, and agriculture or fisheries employment had a higher prevalence of COPD. However, these factors may be related to male gender, old age, and a heavy smoking history, which are already well-known risk factors for COPD. Therefore, multivariate analysis should be performed to define if these factors are independent risk factors for COPD. Marital status was related to smoking history in a previous study, ${ }^{13}$ whereas the present study showed that marital status was not significantly associated with COPD; this result should be re-judged based on previous studies because the total number of unmarried subjects was small ( $\mathrm{n}=41$; representing 419,691 subjects; $1.3 \%$ of the total number of subjects) in this study. 
Table 4 Multivariate analysis of COPD according to smoking history and amount of vitamin C intake

\begin{tabular}{|c|c|c|c|c|}
\hline \multirow{2}{*}{$\begin{array}{l}\text { Smoking } \\
\text { history }\end{array}$} & \multirow[t]{2}{*}{ Vitamin C intake (mg) } & \multicolumn{3}{|c|}{ Multivariate analysis } \\
\hline & & OR & $95 \% \mathrm{Cl}$ & $P$-value \\
\hline \multirow[t]{4}{*}{ Never smoker } & Lowest quartile (QI, <48.50) & Reference & & 0.802 \\
\hline & Low-middle quartile (Q2, 48.50-84.38) & 0.906 & $0.564-1.456$ & \\
\hline & High-middle quartile (Q3, 84.38-|4|.63) & 0.980 & $0.559-1.717$ & \\
\hline & Highest quartile (Q4, >|41.63) & 0.738 & $0.377-1.447$ & \\
\hline \multirow[t]{4}{*}{ Light smoker } & Lowest quartile (QI, <48.50) & Reference & & $0.01 I^{*}$ \\
\hline & Low-middle quartile (Q2, 48.50-84.38) & 1.753 & $0.707-4.346$ & \\
\hline & High-middle quartile (Q3, 84.38-|4|.63) & 1.657 & $0.756-3.630$ & \\
\hline & Highest quartile (Q4, >|41.63) & 0.540 & $0.226-1.290$ & \\
\hline \multirow[t]{4}{*}{ Medium smoker } & Lowest quartile (QI, <48.50) & Reference & & 0.786 \\
\hline & Low-middle quartile (Q2, 48.50-84.38) & 0.637 & $0.211-1.921$ & \\
\hline & High-middle quartile (Q3, 84.38-|4I.63) & 0.612 & $0.213-1.759$ & \\
\hline & Highest quartile (Q4, >|4I.63) & 0.655 & $0.253-1.694$ & \\
\hline \multirow[t]{4}{*}{ Heavy smoker } & Lowest quartile (QI, <48.50) & Reference & & $0.019^{*}$ \\
\hline & Low-middle quartile (Q2, 48.50-84.38) & 0.586 & $0.138-2.484$ & \\
\hline & High-middle quartile (Q3, 84.38-|4I.63) & 0.233 & $0.094-0.576$ & \\
\hline & Highest quartile (Q4, >|4|.63) & 0.375 & $0.140-1.004$ & \\
\hline
\end{tabular}

Note: $* P<0.05$ obtained by multivariate logistic regression analysis with adjustment of age and sex. Abbreviations: $\mathrm{OR}$, odds ratio; $\mathrm{Cl}$, confidence interval.

The main contributing factors for the development of COPD are genetic background, exposure to oxidizing agents, and reduced antioxidant capacity. ${ }^{14,15}$ Dietary antioxidants are responsible for antioxidant defenses in the lungs. ${ }^{16}$ Various nutrients, including vitamin C, retinol, tocopherol, and carotenoids, have been proven to be helpful in altering clinical outcomes of COPD., ${ }^{3,17-19}$ The present study showed a significant shortage of total nutritional, potassium, vitamin A, carotene, retinol, and vitamin $\mathrm{C}$ intake in the COPD group compared to the non-COPD group. However, the difference in nutritional status between the 2 groups may be due to the difference in total nutritional intake. Therefore, again, multivariate analysis would be needed to identify independent risk factors.

To define the independent risk factors for COPD among the mentioned factors, we conducted a multivariate analysis. We revealed that male gender, old age, heavy smoking history, and vitamin $\mathrm{C}$ were independent risk factors for COPD, whereas other factors were not independently significant. Except for the well-known risk factors, vitamin $\mathrm{C}$ was the only independent risk factor. Based on the multivariate analysis, as shown in Table $3,100 \mathrm{mg}$ of vitamin C intake resulted in a risk reduction of $20.0 \%$. In heavy smokers, $\sim 100 \mathrm{mg}$ of vitamin C intake (mean of $30.1 \mathrm{mg}$ in Q1 vs mean of $110.6 \mathrm{mg}$ in Q3) led to a marked risk reduction (76.7\%) for COPD. As humans cannot synthesize vitamin C, intake should be increased via diet. The main source of vitamin $\mathrm{C}$ is vegetables, fruits, and nutritional supplements. One-and-ahalf apples contains $\sim 100 \mathrm{mg}$ of vitamin C. Most nutritional vitamin $\mathrm{C}$ supplements contain $>1,000 \mathrm{mg}$. Therefore, dietary intake of $100 \mathrm{mg}$ vitamin $\mathrm{C}$ is not difficult. However, abuse of vitamin C supplements may lead - yet rarely - to acute renal failure. ${ }^{20}$ Therefore, one should carefully consider vitamin $\mathrm{C}$ supplements.

Vitamin C (also known as ascorbate or L-ascorbic acid) has antioxidant properties, and plays significant roles in the immune system including allergic reaction, maintenance of connective tissue, and even tumor suppression..$^{21-23}$ Low levels of vitamin $\mathrm{C}$ have been associated with significantly more wheezing, dyspnea, and exacerbation of COPD. ${ }^{24-26}$ Dietary vitamin $\mathrm{C}$ has also been shown to lower oxidative stress, increase collagen synthesis, and restore vascular endothelial growth factor levels and proliferation of alveolar cells in the lungs. ${ }^{9}$ Extensive studies have shown that vitamin $\mathrm{C}$ intake provides protection against the development of COPD. ${ }^{1,8,27,28}$ Our results corroborate the findings of these studies.

The results obtained by this study are extremely significant, as this study represents almost half of the total Korean population $(n=23,541,704)$. Joshi et al have previously revealed the effect of dietary antioxidants on COPD in Korea. ${ }^{29}$ We strongly support this previous study with a vast amount of data. Although many researchers have attempted to use KNHANES data, many such studies ignore complex survey design, which leads to biased results, and overstated significance levels. ${ }^{10}$ However, we followed the guidelines suggested by the institute that conducted this complex survey, and therefore, the results of the positive effects of vitamin C on COPD are deemed trustworthy. 
The study has some limitations. First, this is a crosssectional cohort study. It is not possible to ascertain whether a low intake of vitamin $\mathrm{C}$ is the cause or the result of COPD. However, we can assume that it is a causal factor, based on the many previous prospective studies mentioned in this paper. Second, this study was a retrospective study which used already completed survey data. We could not assess occupational or environmental exposure. The nutritional status was also assessed using self-reported questionnaires, with assistance from an interviewer. Measurement of vitamin $\mathrm{C}$ using blood sampling may be more helpful to confirm the nutritional status. Third, we could not ascertain the optimal dose of vitamin $\mathrm{C}$ for preventing COPD because the optimal dose differed according to the smoking history. For example, the association between Q1 and Q3 was stronger than that between Q1 and Q4. Hence, the OR did not follow a linear trend. This might be due to the fact that vitamin $\mathrm{C}$ intake greater than the optimal level does not have any additional effects. This issue should be further studied. Lastly, height, body mass index, dietary fiber, and cured meat intake may be confounding factors in this study.

\section{Conclusion}

This large-scale national study suggests that dietary vitamin C intake is protective against COPD independent of smoking history in the Korean general population.

\section{Acknowledgments}

This manuscript was entirely contributed by the Korean Smoking Cessation Study Group including Jae-Woo Jung, In Ae Kim, Young Sik Park, and Joo Hun Park who assisted with study design, data collection, data analysis, and manuscript preparation.

\section{Disclosure}

The authors report no conflicts of interest in this work.

\section{References}

1. Pirabbasi E, Shahar S, Manaf ZA, Rajab NF, Manap RA. Efficacy of ascorbic acid (vitamin C) and/N-acetylcysteine (NAC) supplementation on nutritional and antioxidant status of male chronic obstructive pulmonary disease (COPD) patients. J Nutr Sci Vitaminol (Tokyo). 2016;62(1): 54-61.

2. Schunemann HJ, Grant BJ, Freudenheim JL, et al. The relation of serum levels of antioxidant vitamins $\mathrm{C}$ and $\mathrm{E}$, retinol and carotenoids with pulmonary function in the general population. Am J Respir Crit Care Med. 2001;163(5):1246-1255.

3. Ochs-Balcom HM, Grant BJ, Muti P, et al. Antioxidants, oxidative stress, and pulmonary function in individuals diagnosed with asthma or COPD. Eur J Clin Nutr. 2006;60(8):991-999.
4. Biswas S, Hwang JW, Kirkham PA, Rahman I. Pharmacological and dietary antioxidant therapies for chronic obstructive pulmonary disease. Curr Med Chem. 2013;20(12):1496-1530.

5. Varraso R, Fung TT, Hu FB, Willett W, Camargo CA. Prospective study of dietary patterns and chronic obstructive pulmonary disease among US men. Thorax. 2007;62(9):786-791.

6. Isbaniah F, Wiyono WH, Yunus F, Setiawati A, Totzke U, Verbruggen MA. Echinacea purpurea along with zinc, selenium and vitamin $\mathrm{C}$ to alleviate exacerbations of chronic obstructive pulmonary disease: results from a randomized controlled trial. J Clin Pharm Ther. 2011;36(5): 568-576.

7. Hu G, Cassano PA. Antioxidant nutrients and pulmonary function: the Third National Health and Nutrition Examination Survey (NHANES III). Am J Epidemiol. 2000;151(10):975-981.

8. Keranis E, Makris D, Rodopoulou P, et al. Impact of dietary shift to higher-antioxidant foods in COPD: a randomised trial. Eur Respir J. 2010;36(4):774-780.

9. Koike K, Ishigami A, Sato Y, et al. Vitamin C prevents cigarette smoke-induced pulmonary emphysema in mice and provides pulmonary restoration. Am J Respir Cell Mol Biol. 2014;50(2):347-357.

10. Kim Y, Park S, Kim NS, Lee BK. Inappropriate survey design analysis of the Korean National Health and Nutrition Examination Survey may produce biased results. J Prev Med Public Health. 2013;46(2):96-104.

11. Kim Y. The Korea National Health and Nutrition Examination Survey (KNHANES): current status and challenges. Epidemiol Health. 2014; 36:e2014002.

12. Global initiative for chronic Obstructive Lung Disease. Global strategy for diagnosis, management and prevention of COPD. 2016. Available from: http://goldcopd.org/global-strategy-diagnosis-managementprevention-copd-2016/. Accessed August 4, 2016.

13. Kim SM, Jung JW, Park IW, et al. Gender differences in relations of smoking status, depression, and suicidality in Korea: findings from the Korea National Health and Nutrition Examination Survey 2008-2012. Psychiatry Investig. 2016;13(2):239-246.

14. MacNee W. Pulmonary and systemic oxidant/antioxidant imbalance in chronic obstructive pulmonary disease. Proc Am Thorac Soc. 2005;2(1): $50-60$.

15. Siedlinski M, Postma DS, van Diemen CC, Blokstra A, Smit HA, Boezen HM. Lung function loss, smoking, vitamin $\mathrm{C}$ intake, and polymorphisms of the glutamate-cysteine ligase genes. Am J Respir Crit Care Med. 2008;178(1):13-19.

16. Heffner JE, Repine JE. Pulmonary strategies of antioxidant defense. Am Rev Respir Dis. 1989;140(2):531-554.

17. McKeever TM, Lewis SA, Smit HA, Burney P, Cassano PA, Britton J. A multivariate analysis of serum nutrient levels and lung function. Respir Res. 2008;9:67.

18. Edge R, McGarvey DJ, Truscott TG. The carotenoids as anti-oxidants a review. J Photochem Photobiol B. 1997;41(3):189-200.

19. Grievink L, de Waart FG, Schouten EG, Kok FJ. Serum carotenoids, alpha-tocopherol, and lung function among Dutch elderly. Am J Respir Crit Care Med. 2000;161(3 Pt 1):790-795.

20. McHugh GJ, Graber ML, Freebairn RC. Fatal vitamin C-associated acute renal failure. Anaesth Intensive Care. 2008;36(4):585-588.

21. Deruelle F, Baron B. Vitamin C: is supplementation necessary for optimal health? J Altern Complement Med. 2008;14(10):1291-1298.

22. Seo MS, Kim JK, Shim JY. High-dose vitamin C promotes regression of multiple pulmonary metastases originating from hepatocellular carcinoma. Yonsei Med J. 2015;56(5):1449-1452.

23. Seo JH, Kwon SO, Lee SY, et al. Association of antioxidants with allergic rhinitis in children from Seoul. Allergy Asthma Immunol Res. 2013;5(2):81-87.

24. Tug T, Karatas F, Terzi SM. Antioxidant vitamins (A, C and E) and malondialdehyde levels in acute exacerbation and stable periods of patients with chronic obstructive pulmonary disease. Clin Invest Med. 2004;27(3):123-128.

25. Schwartz J, Weiss ST. Dietary factors and their relation to respiratory symptoms. The Second National Health and Nutrition Examination Survey. Am J Epidemiol. 1990;132(1):67-76. 
26. Bodner C, Godden D, Brown K, Little J, Ross S, Seaton A. Antioxidant intake and adult-onset wheeze: a case-control study. Aberdeen WHEASE Study Group. Eur Respir J. 1999;13(1):22-30.

27. Tsiligianni IG, van der Molen T. A systematic review of the role of vitamin insufficiencies and supplementation in COPD. Respir Res. 2010;11:171.

28. Kodama Y, Kishimoto Y, Muramatsu Y, et al. Antioxidant nutrients in plasma of Japanese patients with chronic obstructive pulmonary disease (COPD), asthma-COPD overlap syndrome, and bronchial asthma. Clin Respir J. Epub 2015 Dec 14.
29. Joshi P, Kim WJ, Lee SA. The effect of dietary antioxidant on the COPD risk: the community-based KoGES (Ansan-Anseong) cohort. Int J Chron Obstruct Pulmon Dis. 2015;10:2159-2168.

\section{Publish your work in this journal}

The International Journal of COPD is an international, peer-reviewed journal of therapeutics and pharmacology focusing on concise rapid reporting of clinical studies and reviews in COPD. Special focus is given to the pathophysiological processes underlying the disease, intervention programs, patient focused education, and self management protocols.

\section{Dovepress}

This journal is indexed on PubMed Central, MedLine and CAS. The manuscript management system is completely online and includes a very quick and fair peer-review system, which is all easy to use. Visit $\mathrm{http}: / / \mathrm{www}$.dovepress.com/testimonials.php to read real quotes from published authors. 